\title{
Theoretical perspectives of the HCD integration in software development process
}

\author{
Rogayah Abdul Majid, Nor Laila Md. Noor, Wan Adilah Wan Adnan \\ Department of Computer and Mathematical Sciences, Universiti Teknologi MARA, Malaysia
}

\begin{tabular}{l} 
Article Info \\
\hline Article history: \\
Received May 29, 2019 \\
Revised Jul 30, 2019 \\
Accepted Aug 13, 2019 \\
\hline
\end{tabular}

\section{Keywords:}

Hcd integration

Human centered design

Management perspectives organization resources

Theoretical

\begin{abstract}
HCD is an approach that covers all of the human aspects including aesthetic and ergonomics, which will provide a better approach in strengthening the HCI approaches to strengthen the software development process. Lack of guidelines to guide the software practitioners to adopt the HCD in software development process become the main concern in this study. Among the problems that faced by the organizations that have adopted HCD, including problem of managing the resources such as human, financial and infrastructure. Therefore, this study used a theoretical lens to get a better understanding of HCD integration form management perspective, namely operational, tactical (management) and strategy perspective in software development process. Furthermore, the HCDP model is employed in this study because it covers the HCD activities from the project planning stage to the implementation stage of the software development process and it emphasizes on the larger scope of human factors and require broader skills in software development process. As a result, a conceptual model of HCD integration has been developed which emphasizes on the importance of managing the resources and long term strategic planning for the organization. This is due to long term strategic planning and managing organization resources appropriately will contribute to the success of the organization which will increase organizational performance.
\end{abstract}

Copyright (C) 2020 Institute of Advanced Engineering and Science. All rights reserved.

\section{Corresponding Author:}

Rogayah Abdul Majid,

Department of Computer and Mtahematical Sciences,

Universiti Teknologi MARA.

40450 Shah Alam, Selangor, Malaysia

Email: rogayah@tmsk.uitm.edu.my

\section{INTRODUCTION}

HCD is an approach that covers all of the human aspects including aesthetic and ergonomics, which will provide a better approach in strengthening the $\mathrm{HCI}$ approaches to strengthen the software development process [1]. Several problems were cited by organizations that attempted to adopt HCD in software development process. The problems that arise are said to be related to the interacting factors such as task, organizational and situational factors that can influence the development of the software [2]. Besides lack of of HCI and usability experts [3], the lack of systematic approach, inadequate knowledge and unclear responsibilities among the practitioners [4], the lack of guidelines to guide the software practitioners to adopt the HCD and usability in software development process [5] become the main concern in this study.

This study argued that the HCD adoption needs to be addressed from a technology management perspective that position HCD as IT capability in producing quality software. In addition, among the problems faced by the organizations that have adopted HCD include problems of managing the resources such as human, financial and infrastructure in the organizations [6, 7]. Three theoretical perspectives are presented that represent different perspectives of HCD adoption. This study uses a theoretical lens to get a better understanding of the relationship between operational, tactical (management) and strategy component 
in software development process. This is due to the theoretical lens is used to view and identify the phenomena from multiple perspectives in the context of the problem under study [8].

\section{MANAGEMENT PERSPECTIVES}

Management perspective is divided into three perspectives, namely operational perspective, management or tactical perspectives and strategic perspectives. The operational is the activities of the organization to transform inputs into final outputs. In this study, operational perspective is referring to the organizational focus on their daily activities of their resources to achieve specific goals of the organization which involve with tools, method and process of user involvement in the software development life cycle (SDLC). In other word, it explains how practitioners incorporate the HCD approach in software development process and how HCD activities should contribute to developing the software.

The management or tactical is referring to the management of resources to gain efficiency and effectiveness of the organization. Resources can be divided into physical equipment such as facilities (equipment), financial and human resources (knowledge and skills) in order to gain competitive advantage. Managing resources include planning, organizing, motivating, staffing and controlling. In the software development industry, management is referring to planning, evaluating and coordinating the operation in software development process. The role of IT manager as a management level is including managing the projects, budgeting, managing the operation and deal with new technology [9]. Management level has responsibility to manage the human resources, facilities and finances of the organization. This is due to organizational resources contribute to the organization to generate competitive advantage and increase the performance of the organization [10].

The strategic perspective is an organization has to plan the strategy for the organization to increase their profit and satisfy the user of their product. The organization has to make a decision how to use their resources and create something better than their competitors to gain the competitive advantage in the industry [11]. Strategic planning can be explained as an action to be considered by an organization using their resources to achieve long term objective. Eser et al., [12] defines strategic planning is a process which the organization evaluates capabilities, opportunities and risk of the resources in order to carry out the mission of the organization. The organization is responsible to plan their resources at corporate, business and functional level.

\section{THEORETICAL PERSPECTIVES}

This paper refers to Human Centered Design Processes (HCDP) developed by Earthy [13] based on HCD lifecycle process proposed by the ISO TR 18529. Earthy has identified the processes for each of the components in the ISO TR 18529 standard. Based on these base practices, Earthy has developed the Human Centered Design Processes (HCDP) Model (Earthy, 1999).

Earthy [13] has developed Human Centered Design Processes (HCDP) based on HCD lifecycle process proposed by the ISO TR 18529. Earthy has identified the processes for each of the components in the ISO TR 18529 standard. Based on the ISO TR 18529 standard, Earthy has refined and categorized the HCD lifecycle process into three categories namely operational, tactical and strategic. The HCD1 base practice is categorized as strategy process which fall under higher level management category. The HCD 2 base practice is categorized as a tactical or a managerial process which fall under middle level management category. The HCD3- HCD7 base practices are categorized as an operational processes.

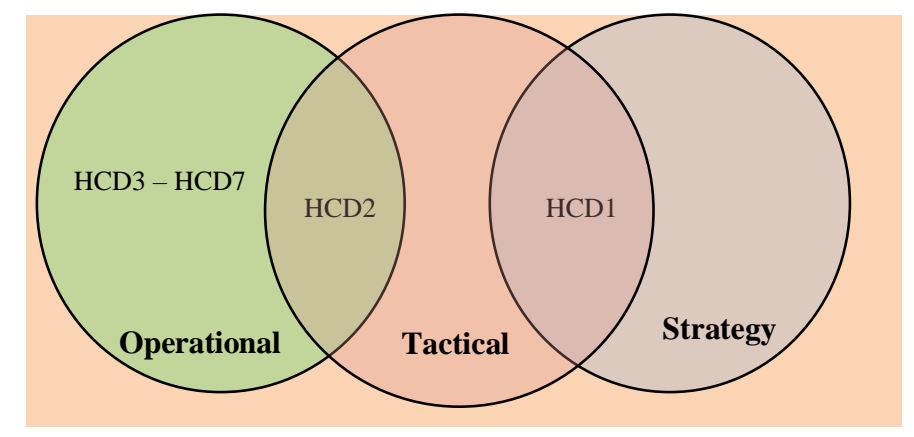

Figure 1. Inter-related between operational, tactical and strategy components 
The HCDP Model is defined processes or activities that carry out a human centered approach at each level in software development process [14]. The HCDP model is employed because, it is argued to offer "better defined user and organizational requirements, design support, usability testing procedures and postdelivery feedback" [15]. HCDP covers the HCD activities from the project planning stage to the implementation stage of the software development lifecycle process. Furthermore, this model emphasizes on the larger scope of human factors and require broader skills in software development process.

The HCDP Model consists of seven set of base practices. The practices illustrate the activities or processes that have to be done, which focuses on the human centered process during software development life cycle. Based on the ISO TR 18529 standard [16], Earthy has refined and categorized the HCDP processes into three components namely operational, tactical and strategic.

Refer to Figure 1, HCD1 is focused on human centered processes at a higher management level, HCD2 focuses on human centered processes at management (tactical) level and HCD 3-7 are emphasizing on the human centered process during software development life cycle at operational level. The Inter-related between operational, tactical and strategy components is shown in Figure 2. In tactical component, the HCDP model addresses on plan and manage the HCD process (HCD2) which is also part of operational components. On the other hand, in a strategy component Earthy address in ensuring HCD content in system strategy (HCD1) which only focus on software development process which is also part of tactical component. This is due to, the strategy focuses on high level decision making.

\section{HCD INTEGRATION FROM MANAGEMENT PERSPECTIVES}

Even though the HCDP model covers the process at the tactical (management level) and strategy (higher management level), but its focus more on human centered activities at the operational level. In other word, human centered process focuses more on operational perspectives and little on the tactical and strategic perspectives. The HCDP process overlooks the importance of managing the resources such as human resource (HR), finance and facilities, and strategic planning for the organizations. However, this model failed to discuss on managing of the resources. Furthermore, this model does not take into account the importance of strategic planning of the resources in the organization to gain competitive advantage. Therefore, this study will address on the managing of resources which include human resource (HR), facilities and financial at management level and strategic planning at strategy level as shown in Figure 2.

The conceptual model shown in Figure 2, illustrates the integration of HCD from management perspectives. This model emphasizes on the importance of managing the resources such as human resource (HR), finance and facilities. Managing human resource is referred to managing staff competency. Staff competency is referring to staffs that have knowledge, skill, attitude and behavior and other personal attributes that the organization expected to have to contribute successfully within the organizational context. This is due to, the staff who has competency with the organizational leadership will contribute to the success of the organization [17]. Financial management is management of organization funds to create wealth for the organization by allocating the budget to manage the resources in the organization. This is because financial management is important for the organization to keep track the resources and allocate them efficiently [18]. Furthermore, financial management has a great influence on the decision of the organization.

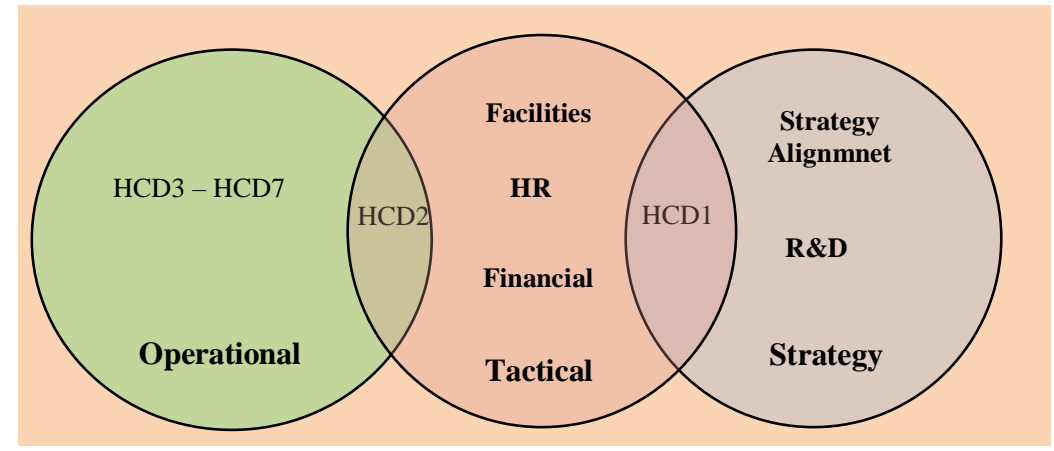

Figure 2. Conceptual model of HCD integration

On the other hand, management has responsibility in providing the allocation of infrastructure in the organization. Managing the facilities including managing the equipment, systems, software, and services 
used in common within the department in the organization. It is much cheaper to have in-house tools and facilities that can be used by all the staffs in the organization. The availability to assess the infrastructure of the organization will make HCD adoption is cost effective, efficient and effective [19].

Furthermore, the DHCP model does not take into account the trend of the technology and long term planning in order to be sustained in the software development industry. Therefore, this study will address on the strategy of the organization to align HCD with current technology, and organization strategy in research and development (R\&D) as shown in Figure 3. Strategic alignment is referring to the strategy of the organization to align HCD with current technology. The capability of the organization to set alignment between HCD and current technology can be a factor for competitive advantage and can improve business performance [20]. Furthermore, aligning HCD strategy with current technology, the organization can maximize their investment which can give positive impact of the organizational business performance [21]. This was supported by Chan et al. [22] and Hooper [21] claimed that there is a strong relationship between strategy alignment and business performance in the organization.

The organization has to continue on searching for new opportunities through research and development (R\&D). This is because exploring human centered approach in $R \& D$ will lead to the creation of valuable innovation that can be commercialized and socialized [23]. Furthermore, the organization has to take advantage of existing resources to continue improving knowledge and process [24] HCD implementation. This due to, through $\mathrm{R} \& \mathrm{D}$, organizations can change and use the resources to continue innovating [25] in HCD in order to be sustained in competitive advantage.

\section{CONCLUSION}

Lack of guidelines to guide the software practitioners to adopt the HCD in software development process, has resulted problem related to the interacting factors such as task, organizational and situational factors that can influence the development of the software. Organizational resources such as human resource, facilities and finance need to be managed appropriately because it will contribute to the success of the organization. The trend of the technology and long term planning of the organization needs to take into account by the organization in order to be sustained in the software development industry.

\section{REFERENCES}

[1] Majid. R. A., Noor, N.M. and Adnan, W. A. W, Strengthening the HCI Approaches in the Software Development Process. World Academy of Science, Engineering and Technology. Vol 64. 2012.

[2] Boy, G. A. A, "Human-Centered Design Approach," The Handbook of Human-Machine Interaction, 2017.

[3] Cardella, M.E, Zoltowski, C.B. and Oakes, W.C, 2012, "Developing Human-Centered Design Approaches," Preparing Professionals to Address Complex Problems. Proceeding of SIGDOC'12. 2012.

[4] Viikki, K, and Palviainen, J, "Integrating Human-Centered Design into Software Development: An Action Research Study in the Automation Industry, "37th EUROMICRO Conference on Software Engineering and Advanced Applications, 2011.

[5] Kashfi P, Nilsson A, Feldt R, "Integrating User eXperience practices into software development processes: implications of the UX characteristics", PeerJ Computer Science 3:e130. 2017. https://doi.org/10.7717/peerj-cs.130

[6] Junginger, S, "A Different Role for Human-Centered Design within the Organization", Conference Proceedings of the 6th Annual Conference of the European Academy of Design, Bremen. 2005.

[7] Othman. R, Arshad. R, Ari, N. A. and Arif, S. M. M, "Organizational Resources and Sustained Competitive Advantage of Cooperative Organizations in Malaysia", Social and Behavioral Sciences 170, 120 - 127. 2015.

[8] Creswell, J. W, "Qualitative Inquiry research Design: Choosing Among Five Approaches (Second Ed.) ", Thousand Oaks, California: Sage Publications.2007.

[9] Holtsnider B. and Jaffe. B. D. IT Manager's Handbook, The Business Edition. ACM SIGSOFT Software Engineering Notes. Vol 36 No. 5. 2011.

[10] Ismail, A. I., Rose, R.C., Uli, J. and Abdullah, H, "The Relationship Between Organisational Resources, Capabilities, Systems and Competitive Advantage", Asian Academy of Management Journal, Vol. 17, No. 1, pp. 151-173. 2012.

[11] Majid R.A., Noor N.L.M. and Adnan W.A.W, An Assessment Tool for Measuring Human Centered Design Adoption in Software Development Process. In: Rocha Á., Adeli H., Reis L., Costanzo S. (eds) Trends and Advances in Information Systems and Technologies. WorldCIST'18 2018. Advances in Intelligent Systems and Computing, Vol 746. Springer, Cham. 2018.

[12] Eser, G., Demirbag, O. and Yozgat, U, "The Effects of Family-Business Related Characteristics and Strategic Planning on Corporate Entrepreneurship", Proceeding of Social and Behavioral Sciences. Vol. 58, pp. 906 - 913. 2012.

[13] Earthy, J, "Usability Maturity Model: Processes", Version 2.2, Lloyd's Register, London. 1999.

[14] Jones, B. S and Earthy, J, "Human-Centered Process Integration: The Process Maturity Perspectives", IEEE Explorer. 1999. 
[15] Earthy, J, "Usability Maturity Model: Human Centeredness Scale", Information Engineering Usability Support Centre. 1998.

[16] ISO TR 18529, " Ergonomics of human system Interaction human-centered lifecycle process descriptions", 2000.

[17] Tripathi, K. and Agrawal, M, "Competency Based Management In Organizational Context: A Literature Review", Global Journal of Finance and Management, 16(4): 349-356. 2014.

[18] Ciuhureanu, A. T., Balteş, N., \& Brezai, L, The financial management's role in modern organizations: "Interferences and differences between the management of the accounting activity and the financial management", Annuals Economic Studies Timişoara, XV, 597-600. 2009.

[19] Xia, W., \& King, W. R. Determinants of Organizational IT Infrastructure Capabilities: An Empirical Study. Management Information Systems Research Center Working Paper, 02-10. 2002.

[20] Baker, J, "A Theoretical Framework for Sustained Strategic Alignment and an Agenda for Research", Working Papers on Information Systems. ISSN 1535-6078. 2008.

[21] Jusoh, M. Y., Haron, H. and Kaur, J, "Work Process of Bring Your Own Device to Support Green Computing", Indonesian Journal of Electrical Engineering and Computer Science (IJEECS). Vol. 11, No. 1, July 2018, pp. 137 143. 2018.

[22] Chan, Y.E, Sabherwal, R. and Thatcher, J. B. Antecedents and Outcomes of Strategic IS Alignment: An Empirical Investigation. IEEE Transaction on Engineering Management. VOL. 53, NO. 1. 2006.

[23] Steen, M. Exploring 'human centred' approaches to market research and concept development for creating more value with ICT. Conference Proceeding of COST269. 2003.

[24] Idris, A. S, Anuar, N., Misron, M. M. and Fauzi, F. H. M, The readiness of Cloud Computing: A case study in Politeknik Sultan Salahuddin Abdul Aziz Shah, Shah Alam, International Conference on Computational Science and Technology (ICCST). Page 1-5. 2014.

[25] Boukis, A. Managing Innovation within Organizations. Book Chapter, Product Innovation through Knowledge Management and Social Media Strategies. IGI Global. 2015. 